Supporting information to:

\title{
Polymerization of ternary inclusion complexes of interacting monomer pairs with $\gamma$-cyclodextrin
}

Niels ten Brummelhuis* and Maria T. Heilmann

Department of Chemistry, Humboldt-Universität zu Berlin, Brook-Taylor-Str. 2, 12489 Berlin, Germany.

\section{Copolymerizations}

The copolymerizations of 4VP and SS were performed using the amounts of monomers, solvents, initiator, etc. as shown in Table SI 1-3.

The copolymerizations of S and PFS were performed using the amounts of monomers, solvents, initiator, etc. as shown in Table SI 4-6. 
Table SI 1. Amounts of reactants used in the copolymerizations of 4VP and SS with $\gamma$-CD.

\begin{tabular}{|c|c|c|c|c|c|c|c|c|}
\hline $\begin{array}{c}\gamma \text {-CD: } \\
\text { 4VP:SS }\end{array}$ & & $\gamma-\mathrm{CD}$ & $4 \mathrm{VP}$ & $\mathrm{SS}$ & $\mathrm{DMF}$ & $\begin{array}{c}\text { AAPH } \\
\text { (10 mM } \\
\text { stock) }\end{array}$ & $\mathrm{D}_{2} \mathrm{O}$ & $\begin{array}{c}1 \mathrm{M} \\
\mathrm{HNO}_{3}\end{array}$ \\
\hline \multirow{2}{*}{$4: 1: 7$} & Eq. & 3.8 & 1 & 6.6 & 7.7 & 0.08 & & \\
\hline & Amount & $64.6 \mathrm{mg}$ & $1.4 \mu \mathrm{l}$ & $17.6 \mathrm{mg}$ & $7.7 \mu \mathrm{l}$ & $100 \mu \mathrm{l}$ & $2.9 \mathrm{ml}$ & $2.9 \mu \mathrm{l}$ \\
\hline \multirow{2}{*}{$2: 1: 3$} & Eq. & 2.0 & 1 & 3.1 & 4.0 & 0.04 & & \\
\hline & Amount & $65.2 \mathrm{mg}$ & $2.7 \mu \mathrm{l}$ & $16.1 \mathrm{mg}$ & $7.7 \mu \mathrm{l}$ & $100 \mu \mathrm{l}$ & $2.9 \mathrm{ml}$ & $2.9 \mu \mathrm{l}$ \\
\hline \multirow{2}{*}{$1.5: 1: 2$} & Eq. & 1.5 & 1 & 1.95 & 3.0 & 0.03 & & \\
\hline & Amount & $64.5 \mathrm{mg}$ & $3.6 \mu \mathrm{l}$ & $13.4 \mathrm{mg}$ & $7.7 \mu \mathrm{l}$ & $100 \mu \mathrm{l}$ & $2.9 \mathrm{ml}$ & $2.9 \mu \mathrm{l}$ \\
\hline \multirow{2}{*}{$1: 1: 1$} & Eq. & 1.0 & 1 & 1.0 & 2.0 & 0.02 & & \\
\hline & Amount & $65.2 \mathrm{mg}$ & $5.4 \mu \mathrm{l}$ & $10.3 \mathrm{mg}$ & $7.7 \mu 1$ & $100 \mu 1$ & $2.9 \mathrm{ml}$ & $2.9 \mu \mathrm{l}$ \\
\hline \multirow{2}{*}{$1.5: 2: 1$} & Eq. & 0.75 & 1 & 0.5 & 1.5 & 0.015 & & \\
\hline & Amount & $64.7 \mathrm{mg}$ & $7.2 \mu \mathrm{l}$ & $7.3 \mathrm{mg}$ & $7.7 \mu \mathrm{l}$ & $100 \mu \mathrm{l}$ & $2.9 \mathrm{ml}$ & $2.9 \mu \mathrm{l}$ \\
\hline \multirow{2}{*}{$2: 3: 1$} & Eq. & 0.7 & 1 & 0.3 & 1.3 & 0.013 & & \\
\hline & Amount & $64.6 \mathrm{mg}$ & $8.1 \mu \mathrm{l}$ & $5.2 \mathrm{mg}$ & $7.7 \mu \mathrm{l}$ & $100 \mu 1$ & $2.9 \mathrm{ml}$ & $2.9 \mu \mathrm{l}$ \\
\hline \multirow{2}{*}{$4: 7: 1$} & Eq. & 0.6 & 1 & 0.16 & 1.15 & 0.077 & & \\
\hline & Amount & $65.0 \mathrm{mg}$ & $9.4 \mu \mathrm{l}$ & $2.8 \mathrm{mg}$ & $7.7 \mu \mathrm{l}$ & $100 \mu \mathrm{l}$ & $2.9 \mathrm{ml}$ & $2.9 \mu 1$ \\
\hline
\end{tabular}


Table SI 2. Amounts of reactants used in the copolymerizations of 4VP and SS without $\gamma$-CD.

\begin{tabular}{|c|c|c|c|c|c|c|c|c|}
\hline 4VP:SS & & $\gamma-\mathrm{CD}$ & $4 \mathrm{VP}$ & SS & DMF & $\begin{array}{c}\text { AAPH } \\
(10 \mathrm{mM} \\
\text { stock) }\end{array}$ & $\mathrm{D}_{2} \mathrm{O}$ & $\begin{array}{c}1 \mathrm{M} \\
\mathrm{HNO}_{3}\end{array}$ \\
\hline \multirow{2}{*}{$1: 7$} & Eq. & - & 1 & 6.9 & 8.0 & 0.08 & & \\
\hline & Amount & - & $2.7 \mu l$ & $35.6 \mathrm{mg}$ & $7.7 \mu \mathrm{l}$ & $100 \mu \mathrm{l}$ & $1.9 \mathrm{ml}$ & $1.9 \mu \mathrm{l}$ \\
\hline \multirow{2}{*}{$1: 3$} & Eq. & - & 1 & 3.0 & 4.0 & & & \\
\hline & Amount & - & $2.7 \mu \mathrm{l}$ & $15.3 \mathrm{mg}$ & $7.7 \mu l$ & $100 \mu \mathrm{l}$ & $1.9 \mathrm{ml}$ & $1.9 \mu \mathrm{l}$ \\
\hline \multirow{2}{*}{$1: 2$} & Eq. & - & 1 & 2.0 & 3.0 & 0.03 & & \\
\hline & Amount & - & $3.6 \mu \mathrm{l}$ & $13.8 \mathrm{mg}$ & $7.7 \mu \mathrm{l}$ & $100 \mu \mathrm{l}$ & $1.9 \mathrm{ml}$ & $1.9 \mu \mathrm{l}$ \\
\hline \multirow{2}{*}{$1: 1$} & Eq. & - & 1 & 1.0 & 2.0 & 0.019 & & \\
\hline & Amount & - & $10.8 \mu 1$ & $20.4 \mathrm{mg}$ & $7.7 \mu 1$ & $100 \mu \mathrm{l}$ & $1.9 \mathrm{ml}$ & $1.9 \mu \mathrm{l}$ \\
\hline \multirow{2}{*}{$2: 1$} & Eq. & - & 1 & 0.5 & 1.5 & 0.015 & & \\
\hline & Amount & - & $7.2 \mu \mathrm{l}$ & $6.9 \mathrm{mg}$ & $7.7 \mu \mathrm{l}$ & $100 \mu \mathrm{l}$ & $1.9 \mathrm{ml}$ & $1.9 \mu \mathrm{l}$ \\
\hline \multirow{2}{*}{$3: 1$} & Eq. & - & 1 & 0.35 & 1.33 & 0.013 & & \\
\hline & Amount & - & $8.1 \mu \mathrm{l}$ & $5.5 \mathrm{mg}$ & $7.7 \mu \mathrm{l}$ & $100 \mu \mathrm{l}$ & $1.9 \mathrm{ml}$ & $1.9 \mu \mathrm{l}$ \\
\hline \multirow{2}{*}{$7: 1$} & Eq. & - & 1 & 0.16 & 1.14 & 0.011 & & \\
\hline & Amount & - & $18.9 \mu \mathrm{l}$ & $5.9 \mathrm{mg}$ & $7.7 \mu \mathrm{l}$ & $100 \mu \mathrm{l}$ & $1.9 \mathrm{ml}$ & $1.9 \mu \mathrm{l}$ \\
\hline
\end{tabular}

Table SI 3. Amounts of reactants used in the copolymerizations of 4VP and SS with and without $\gamma$-CD that were purified to characterize the polymers.

\begin{tabular}{c|cccccccc}
$\gamma$-CD & & & & & & AAPH & & $1 \mathrm{M}$ \\
4VP:SS & & $\gamma$-CD & $4 \mathrm{VP}$ & $\mathrm{SS}$ & $\mathrm{DMF}$ & $\begin{array}{c}10 \mathrm{mM} \\
\text { stock }\end{array}$ & $\mathrm{D}_{2} \mathrm{O}$ & $\mathrm{HNO}_{3}$ \\
\hline $0: 1: 1$ & Eq. & - & 1 & 1.002 & 1.999 & 0.01997 & & \\
& Amount & - & $10.8 \mu \mathrm{l}$ & $20.7 \mathrm{mg}$ & $15.4 \mu \mathrm{l}$ & $200 \mu \mathrm{l}$ & $5.8 \mathrm{ml}$ & $5.8 \mu \mathrm{l}$ \\
\hline \multirow{2}{*}{$1: 1: 1$} & Eq. & 0.997 & 1 & 1.007 & 1.999 & 0.01997 & & \\
& Amount & $129.5 \mathrm{mg}$ & $10.8 \mu \mathrm{l}$ & $20.8 \mathrm{mg}$ & $15.4 \mu \mathrm{l}$ & $200 \mu \mathrm{l}$ & $5.8 \mathrm{ml}$ & $5.8 \mu \mathrm{l}$ \\
\hline
\end{tabular}


Table SI 4. Amounts of reactants used in the copolymerizations of S and PFS with $\gamma$-CD.

\begin{tabular}{|c|c|c|c|c|c|c|c|c|}
\hline $\begin{array}{l}\gamma \text {-CD: } \\
\text { S:PFS }\end{array}$ & & $\gamma-\mathrm{CD}$ & $\mathrm{S}$ & PFS & DMAc & $\begin{array}{c}\text { DMA } \\
\text { (50 mM } \\
\text { stock) }\end{array}$ & $\begin{array}{c}\text { BPO } \\
(50 \mathrm{mM} \\
\text { stock })\end{array}$ & DMF \\
\hline \multirow{2}{*}{$4: 1: 7$} & Eq. & 4.134 & 1 & 7.165 & 8.203 & 0.409 & 0.409 & \\
\hline & Amount & $65.6 \mathrm{mg}$ & $1.4 \mu \mathrm{l}$ & $12.1 \mu \mathrm{l}$ & $9.3 \mu \mathrm{l}$ & $100 \mu \mathrm{l}$ & $100 \mu \mathrm{l}$ & $1 \mathrm{ml}$ \\
\hline \multirow{2}{*}{$2: 1: 3$} & Eq. & 2.014 & 1 & 2.973 & 3.960 & 0.197 & 0.197 & \\
\hline & Amount & $66.2 \mathrm{mg}$ & $2.9 \mu \mathrm{l}$ & $10.4 \mu \mathrm{l}$ & $9.3 \mu \mathrm{l}$ & $100 \mu \mathrm{l}$ & $100 \mu \mathrm{l}$ & $1 \mathrm{ml}$ \\
\hline \multirow{2}{*}{$1.5: 1: 2$} & Eq. & 1.488 & 1 & 2.007 & 3.022 & 0.151 & 0.151 & \\
\hline & Amount & $64.1 \mathrm{mg}$ & $3.8 \mu \mathrm{l}$ & $9.2 \mu \mathrm{l}$ & $9.3 \mu \mathrm{l}$ & $100 \mu \mathrm{l}$ & $100 \mu \mathrm{l}$ & $1 \mathrm{ml}$ \\
\hline \multirow{2}{*}{$1: 1: 1$} & Eq. & 1.02 & 1 & 1.004 & & 0.04 & 0.04 & \\
\hline & Amount & $65.9 \mathrm{mg}$ & $5.7 \mu \mathrm{l}$ & $6.9 \mu \mathrm{l}$ & & $200 \mu 1$ & $200 \mu \mathrm{l}$ & $1 \mathrm{ml}$ \\
\hline \multirow{2}{*}{$1.5: 2: 1$} & Eq. & 0.752 & 1 & 0.502 & 1.511 & 0.0753 & 0.0753 & \\
\hline & Amount & $64.8 \mathrm{mg}$ & $7.6 \mu \mathrm{l}$ & $4.6 \mu \mathrm{l}$ & $9.3 \mu \mathrm{l}$ & $100 \mu \mathrm{l}$ & $100 \mu \mathrm{l}$ & $1 \mathrm{ml}$ \\
\hline \multirow{2}{*}{$2: 3: 1$} & Eq. & 0.682 & 1 & 0.337 & 1.335 & 0.067 & 0.067 & \\
\hline & Amount & $66.5 \mathrm{mg}$ & $8.6 \mu \mathrm{l}$ & $3.5 \mu \mathrm{l}$ & $9.3 \mu \mathrm{l}$ & $100 \mu \mathrm{l}$ & $100 \mu \mathrm{l}$ & $1 \mathrm{ml}$ \\
\hline \multirow{2}{*}{$4: 7: 1$} & Eq. & 0.569 & 1 & 0.141 & 1.149 & 0.057 & 0.057 & \\
\hline & Amount & $64.5 \mathrm{mg}$ & $10.0 \mu \mathrm{l}$ & $1.7 \mu \mathrm{l}$ & $9.3 \mu \mathrm{l}$ & $100 \mu \mathrm{l}$ & $100 \mu \mathrm{l}$ & $1 \mathrm{ml}$ \\
\hline
\end{tabular}


Table SI 5. Amounts of reactants used in the copolymerizations of S and PFS without $\gamma$-CD.

\begin{tabular}{|c|c|c|c|c|c|c|c|c|}
\hline $\begin{array}{l}\gamma \text {-CD: } \\
\text { S:PFS }\end{array}$ & & $\gamma-\mathrm{CD}$ & $\mathrm{S}$ & PFS & DMAc & $\begin{array}{c}\text { DMA } \\
(50 \mathrm{mM} \\
\text { stock })\end{array}$ & $\begin{array}{c}\text { BPO } \\
\text { (50 mM } \\
\text { stock) }\end{array}$ & DMF \\
\hline \multirow{2}{*}{$1: 7$} & Eq. & - & 1 & 7.165 & 8.203 & 0.409 & 0.409 & \\
\hline & Amount & - & $1.4 \mu \mathrm{l}$ & $12.1 \mu \mathrm{l}$ & $9.3 \mu \mathrm{l}$ & $100 \mu \mathrm{l}$ & $100 \mu \mathrm{l}$ & $1 \mathrm{ml}$ \\
\hline \multirow{2}{*}{$1: 3$} & Eq. & - & 1 & 2.973 & 3.960 & 0.197 & 0.197 & \\
\hline & Amount & - & $2.9 \mu \mathrm{l}$ & $10.4 \mu \mathrm{l}$ & $9.3 \mu \mathrm{l}$ & $100 \mu \mathrm{l}$ & $100 \mu l$ & $1 \mathrm{ml}$ \\
\hline \multirow{2}{*}{$1: 2$} & Eq. & - & 1 & 2.007 & 3.022 & 0.151 & 0.151 & \\
\hline & Amount & - & $3.8 \mu \mathrm{l}$ & $9.2 \mu \mathrm{l}$ & $9.3 \mu \mathrm{l}$ & $100 \mu \mathrm{l}$ & $100 \mu \mathrm{l}$ & $1 \mathrm{ml}$ \\
\hline \multirow{2}{*}{$1: 1$} & Eq. & - & 1 & 1.004 & & 0.04 & 0.04 & \\
\hline & Amount & - & $5.7 \mu \mathrm{l}$ & $6.9 \mu \mathrm{l}$ & & $200 \mu \mathrm{l}$ & $200 \mu 1$ & $1 \mathrm{ml}$ \\
\hline \multirow{2}{*}{$2: 1$} & Eq. & - & 1 & 0.502 & 1.511 & 0.0753 & 0.0753 & \\
\hline & Amount & - & $7.6 \mu \mathrm{l}$ & $4.6 \mu \mathrm{l}$ & $9.3 \mu \mathrm{l}$ & $100 \mu \mathrm{l}$ & $100 \mu \mathrm{l}$ & $1 \mathrm{ml}$ \\
\hline \multirow{2}{*}{$3: 1$} & Eq. & - & 1 & 0.337 & 1.335 & 0.067 & 0.067 & \\
\hline & Amount & - & $8.6 \mu \mathrm{l}$ & $3.5 \mu \mathrm{l}$ & $9.3 \mu \mathrm{l}$ & $100 \mu \mathrm{l}$ & $100 \mu \mathrm{l}$ & $1 \mathrm{ml}$ \\
\hline \multirow{2}{*}{$7: 1$} & Eq. & - & 1 & 0.141 & 1.149 & 0.057 & 0.057 & \\
\hline & Amount & - & $10.0 \mu \mathrm{l}$ & $1.7 \mu \mathrm{l}$ & $9.3 \mu \mathrm{l}$ & $100 \mu \mathrm{l}$ & $100 \mu \mathrm{l}$ & $1 \mathrm{ml}$ \\
\hline
\end{tabular}

Table SI 6. Amounts of reactants used in the copolymerizations of S and PFS with and without $\gamma$ $\mathrm{CD}$ that were purified to characterize the polymers.

\begin{tabular}{c|cccccccc}
$\gamma$-CD: & & & & & & DMA & BPO & \\
S:PFS & & $\gamma$-CD & S & PFS & DMAc & $\begin{array}{c}(50 \mathrm{mM} \\
\text { stock })\end{array}$ & $\begin{array}{c}(50 \mathrm{mM} \\
\text { stock })\end{array}$ & DMF \\
& & & & & & & & \\
\hline \multirow{2}{*}{$1: 1$} & Eq. & - & 1 & 0.999 & 2.001 & 0.0999 & 0.0999 & \\
& Amount & - & $22.9 \mu \mathrm{l}$ & $27.6 \mu \mathrm{l}$ & $37.1 \mu \mathrm{l}$ & $200 \mu \mathrm{l}$ & $200 \mu \mathrm{l}$ & $1 \mathrm{ml}$ \\
\hline \multirow{2}{*}{$1: 1: 1$} & Eq. & 1.001 & 1 & 0.999 & 2.001 & 0.0999 & 0.0999 & \\
& Amount $259.9 \mathrm{mg}$ & $22.9 \mu \mathrm{l}$ & $27.6 \mu \mathrm{l}$ & $37.1 \mu \mathrm{l}$ & $200 \mu \mathrm{l}$ & $200 \mu \mathrm{l}$ & $1 \mathrm{ml}$ \\
\hline
\end{tabular}




\section{${ }^{1}$ H-NMR titrations}

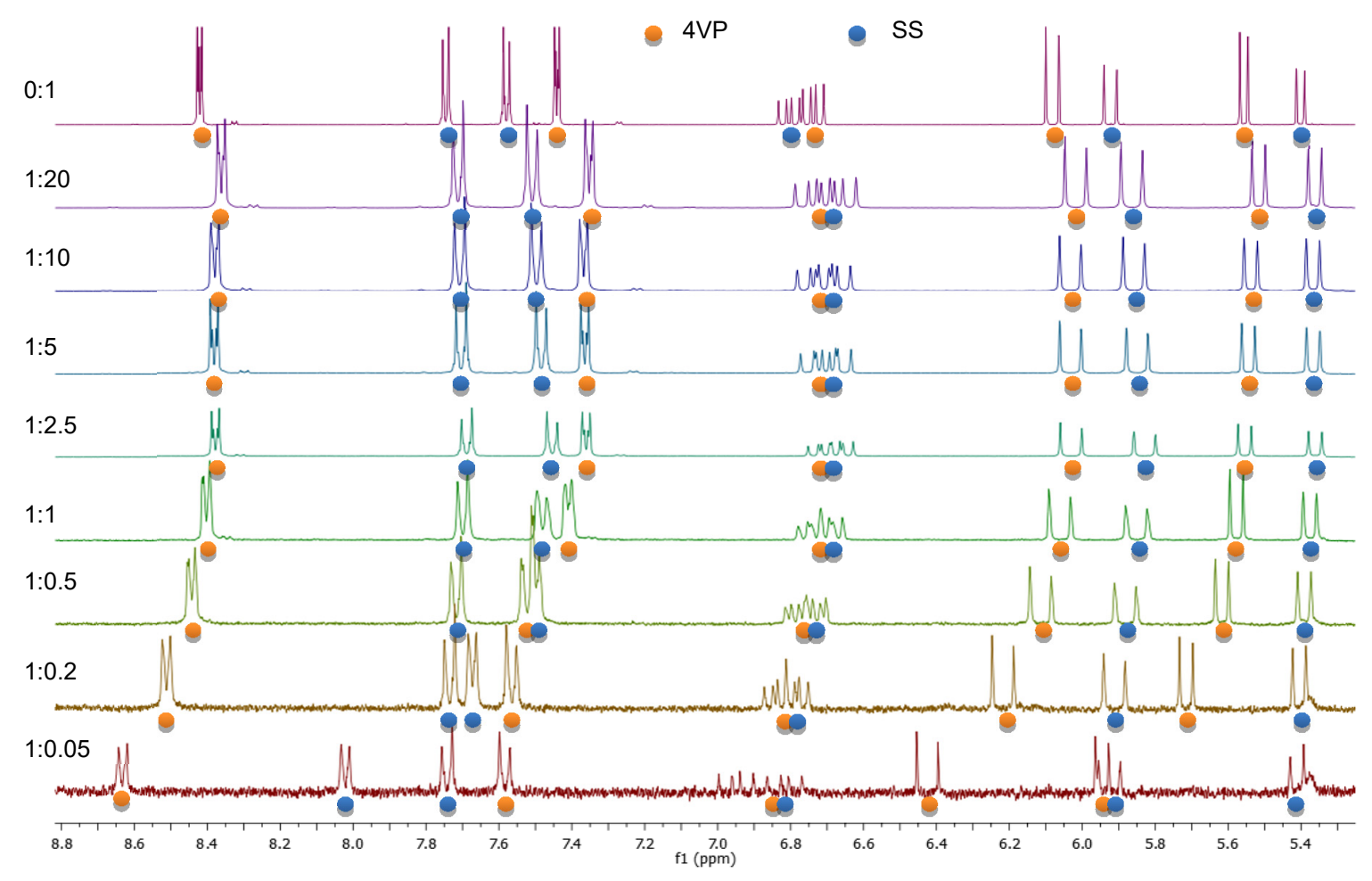

Figure SI 1. Part of the spectra of the ${ }^{1} \mathrm{H}-\mathrm{NMR}$ titration of $\gamma$-CD with $4 \mathrm{VP}$ and SS. The ratios shown to the left of the spectra represent the ratio of $\gamma$-CD:4VP (or $\gamma$-CD:SS, since a 1:1 ratio of 4VP and SS was used). Signals corresponding to 4VP are labeled with orange spheres, SS with blue. 


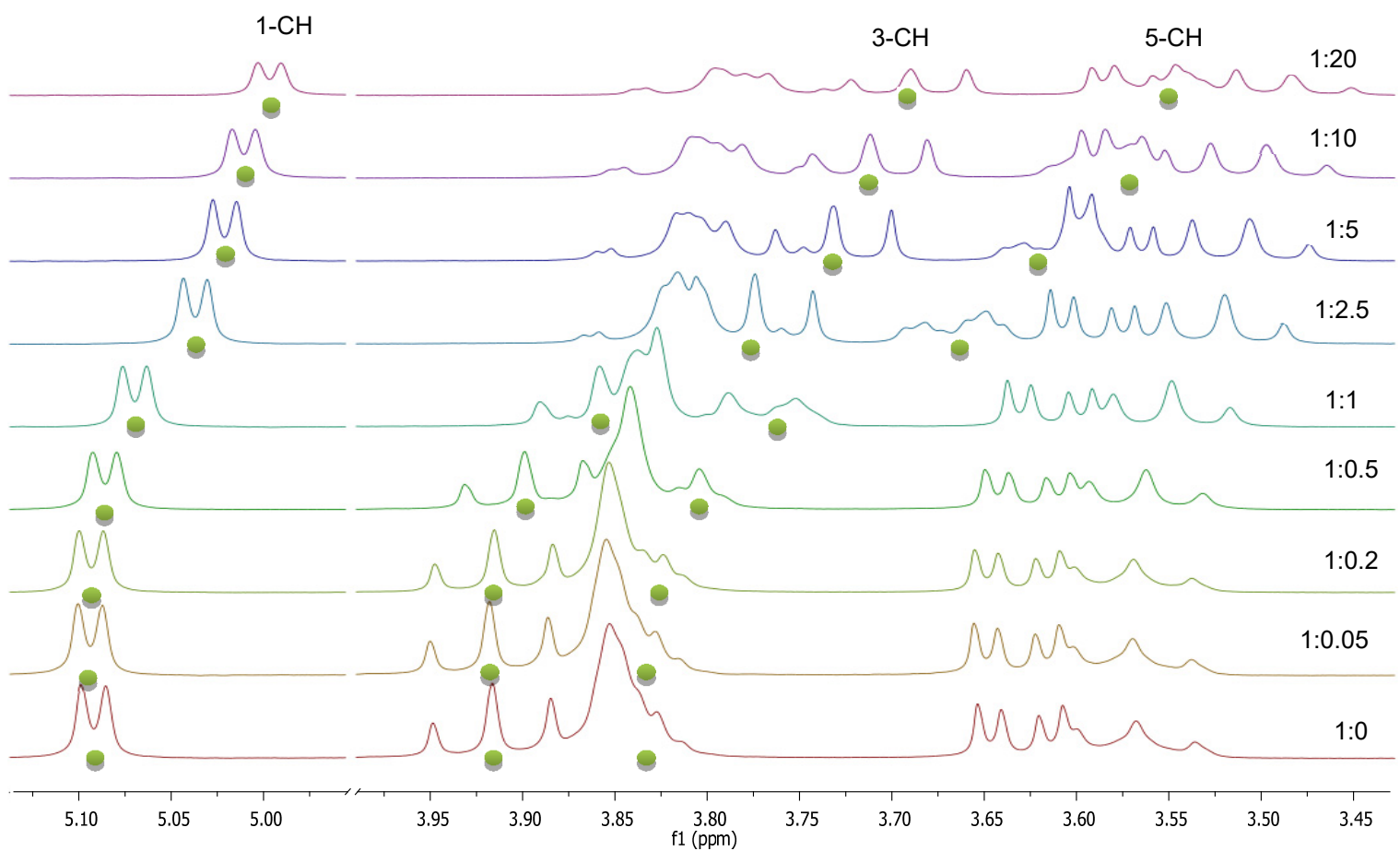

Figure SI 2. Part of the spectra of the ${ }^{1} \mathrm{H}-\mathrm{NMR}$ titration of $\gamma$-CD with $4 \mathrm{VP}$ and SS. The ratios shown to the right of the spectra represent the ratio of $\gamma$-CD:4VP (or $\gamma$-CD:SS, since a 1:1 ratio of 4VP and SS was used). Some important $\gamma$-CD signals are marked with green spheres that serve as a guide to the eyes. 


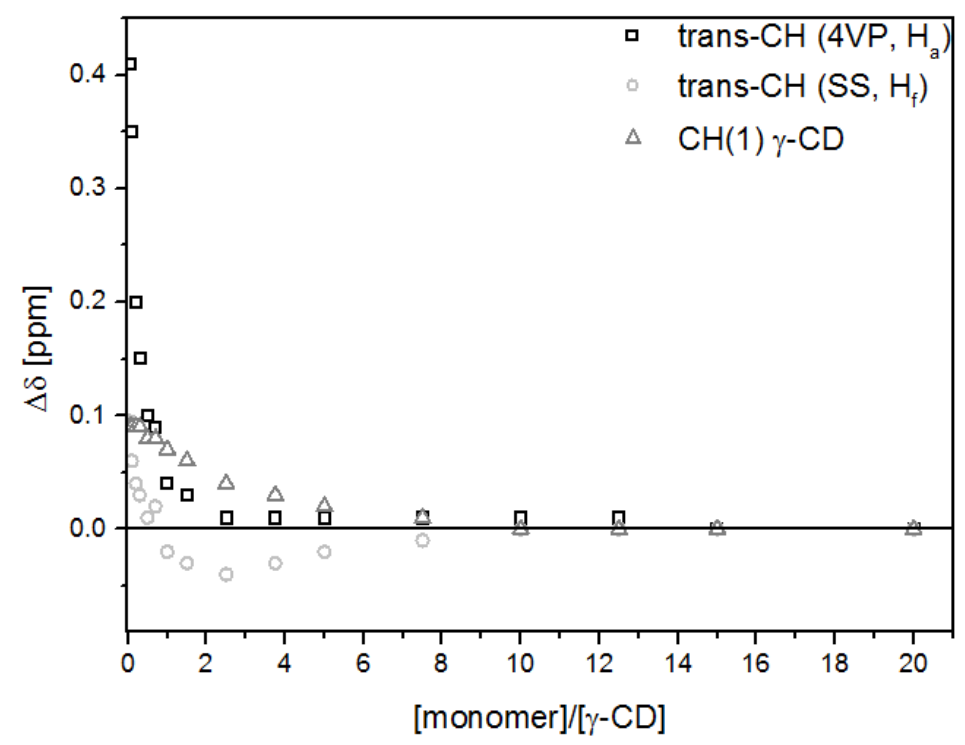

Figure SI 3. Relative change of the chemical shifts with varying ratios of monomer to $\gamma$-CD as found in the ${ }^{1} \mathrm{H}-\mathrm{NMR}$ titration of $\gamma-\mathrm{CD}$ to a solution of 4VP and SS. 


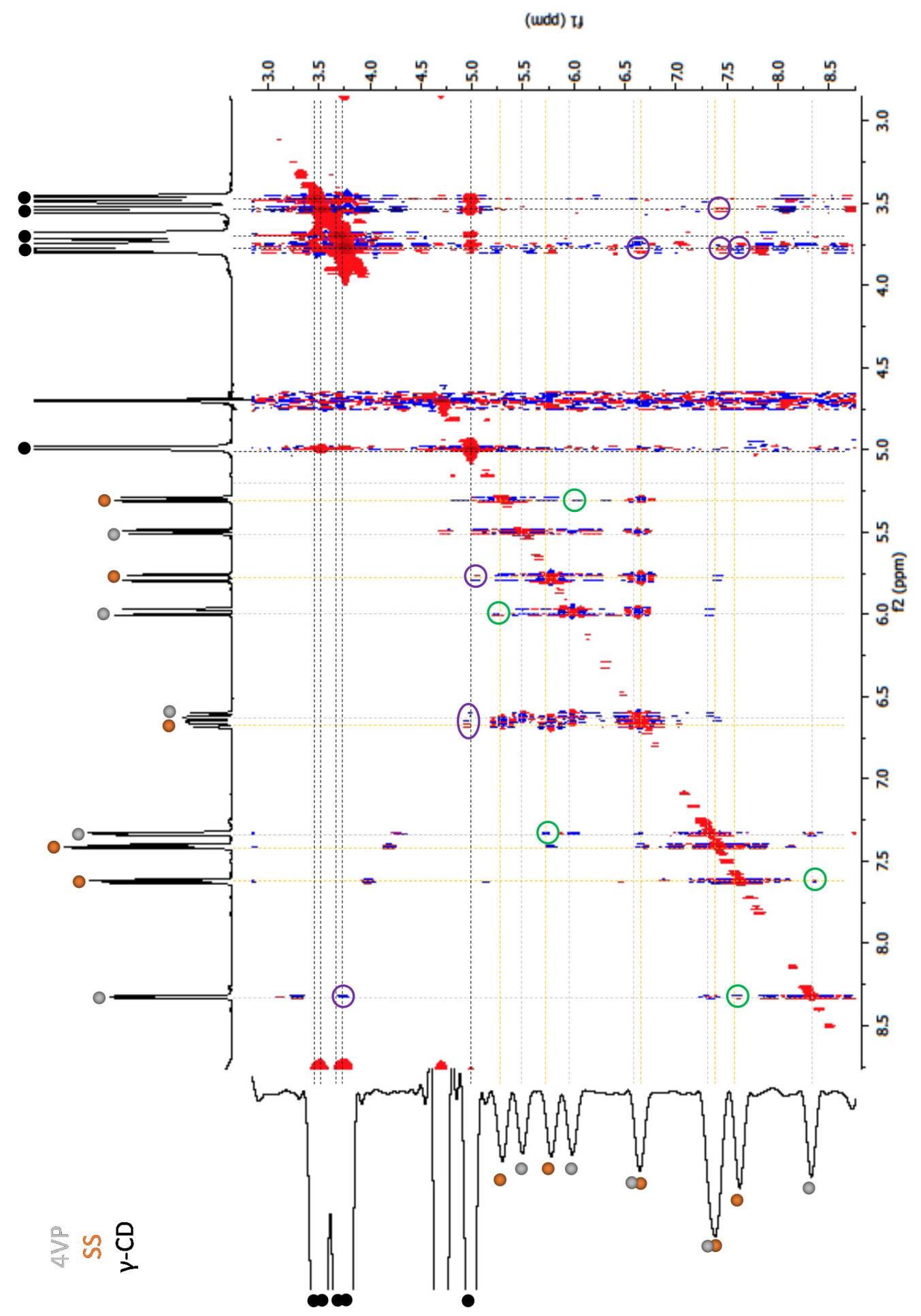

Figure SI 4. ${ }^{1} \mathrm{H}-{ }^{1} \mathrm{H}-\mathrm{NOESY}$ spectrum of a 1:1:1 mixture of $4 \mathrm{VP}$, SS and $\gamma$-CD. Green circles indicate NOE-cross correlation between 4VP and SS, purple circles NOE-cross correlation between either of these monomers and $\gamma-\mathrm{CD}$. 


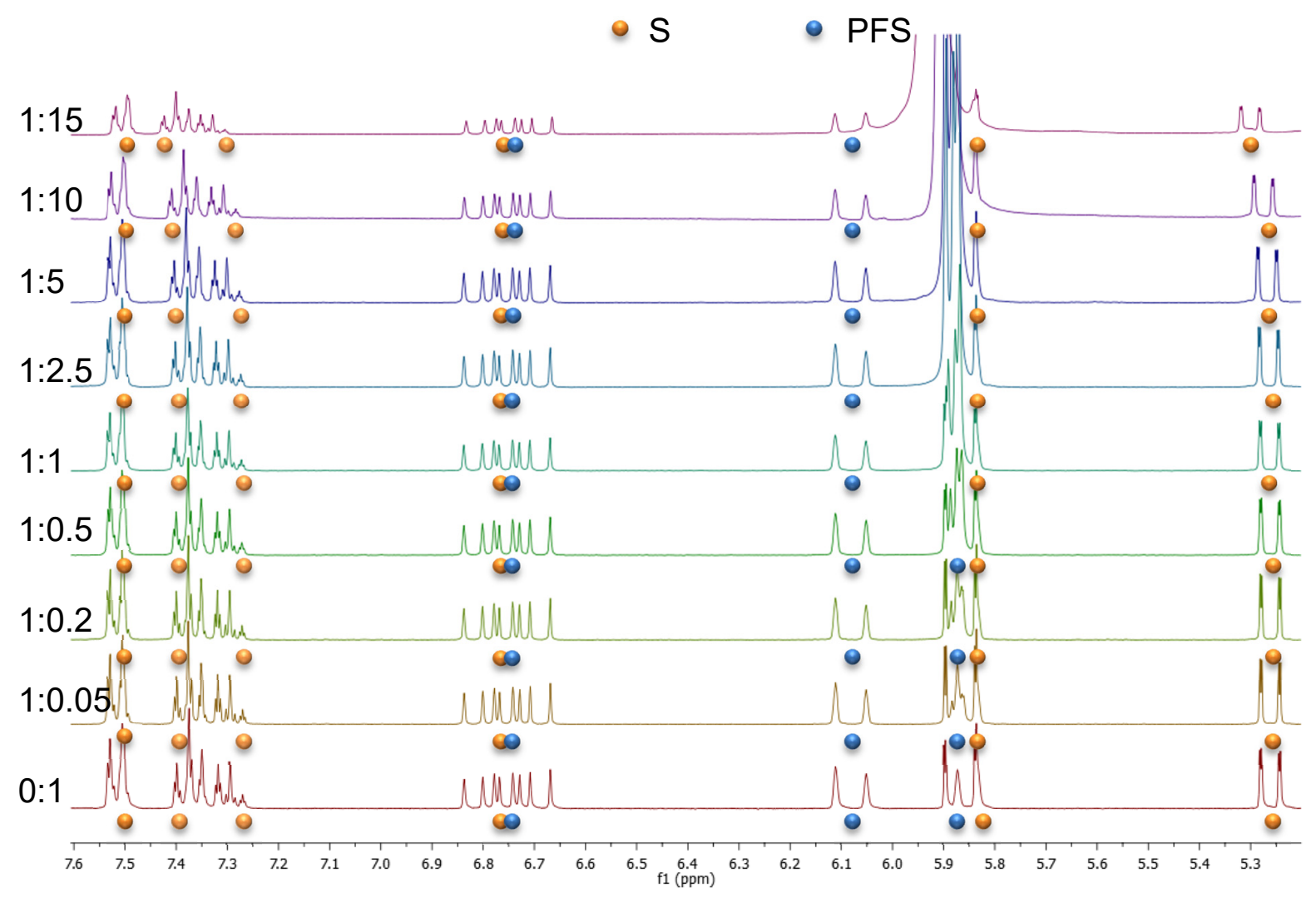

Figure SI 5. Part of the spectra of the ${ }^{1} \mathrm{H}-\mathrm{NMR}$ titration of $\gamma-\mathrm{CD}$ with $\mathrm{S}$ and PFS. The ratios shown to the left of the spectra represent the ratio of $\gamma$-CD:S (or $\gamma$-CD:PFS, since a 1:1 ratio of S and PFS was used). Signals corresponding to S are labeled with orange spheres, PFS with blue. 


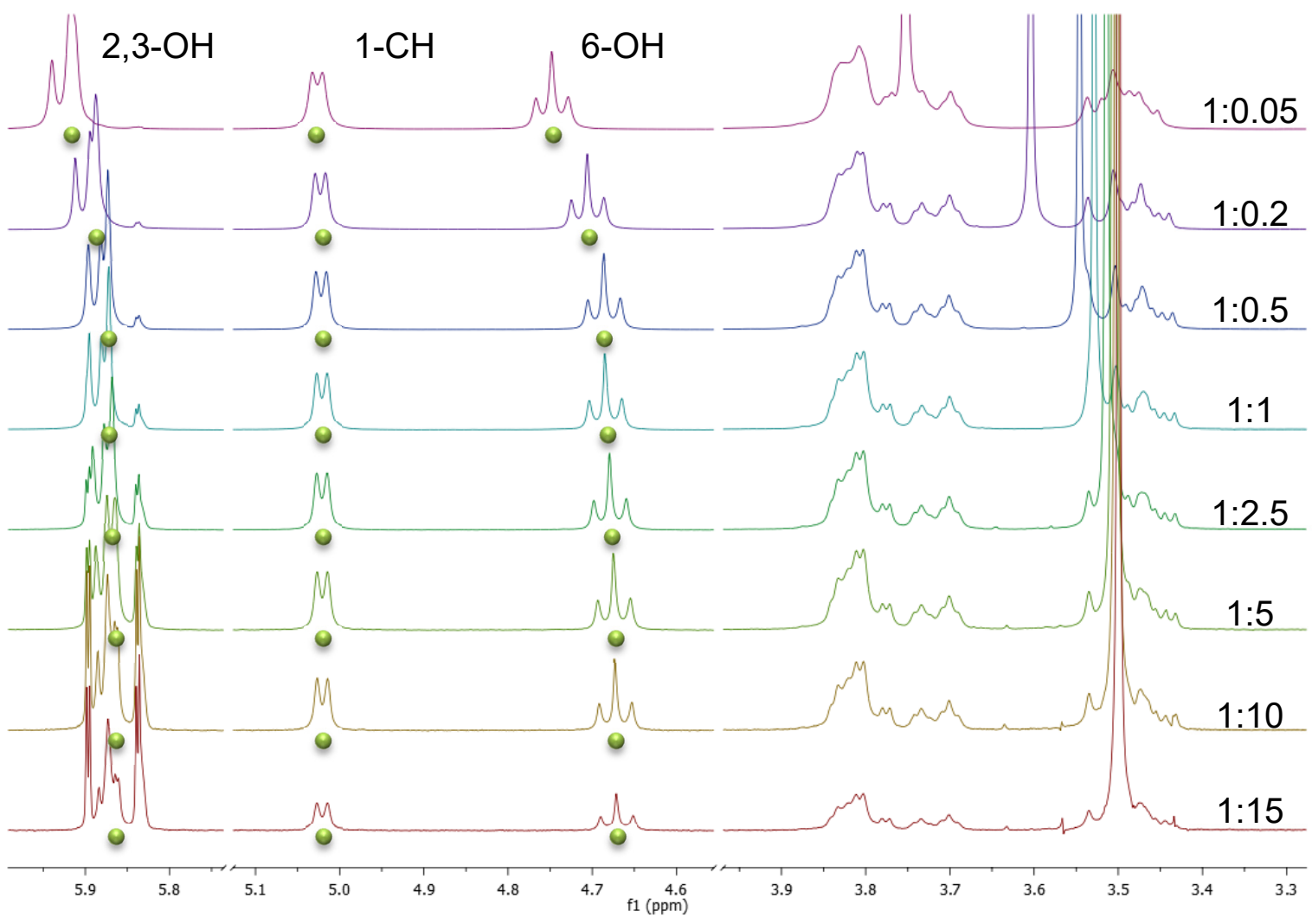

Figure SI 6. Part of the spectra of the ${ }^{1} \mathrm{H}-\mathrm{NMR}$ titration of $\gamma$-CD with $\mathrm{S}$ and PFS. The ratios shown to the right of the spectra represent the ratio of $\gamma$-CD:S (or $\gamma$-CD:PFS, since a 1:1 ratio of S and PFS was used). Some important $\gamma$-CD signals are marked with green spheres that serve as a guide for the eyes. 


\section{Determination of reactivity ratios}

The reactivity ratios for the copolymerizations of 4VP and SS or S and PFS in the absence and presence of $\gamma$-CD were determined by copolymerization of the monomers in different feed ratios and determining the incorporation of the monomers into the polymer at low conversion (Figure SI 7 and 8). The obtained data points and the corresponding fits obtained through different methods are shown in Figure SI 9-12.

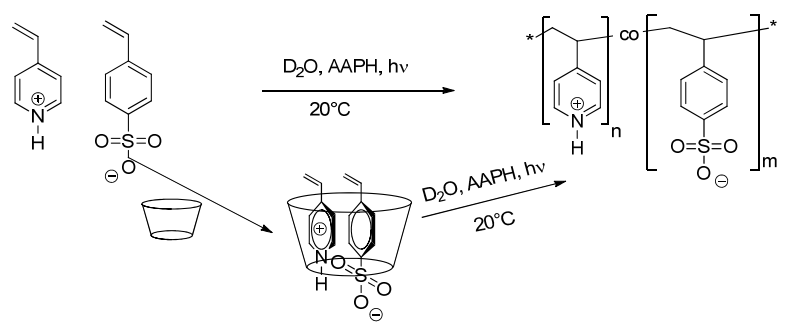

Figure SI 7. Schematic depiction of the copolymerization of 4VP and SS in the absence and presence of $\gamma-\mathrm{CD}$.

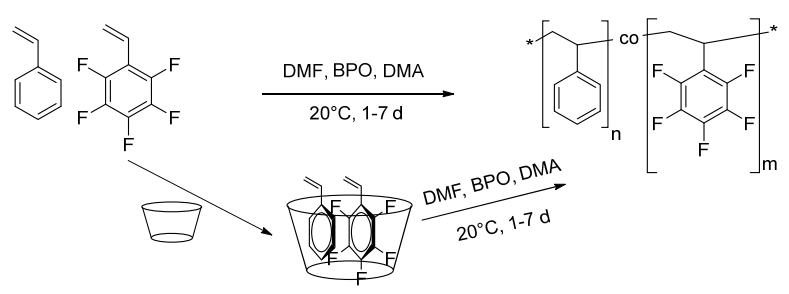

Figure SI 8. Schematic depiction of the copolymerization of S and PFS in the absence and presence of $\gamma-\mathrm{CD}$. 

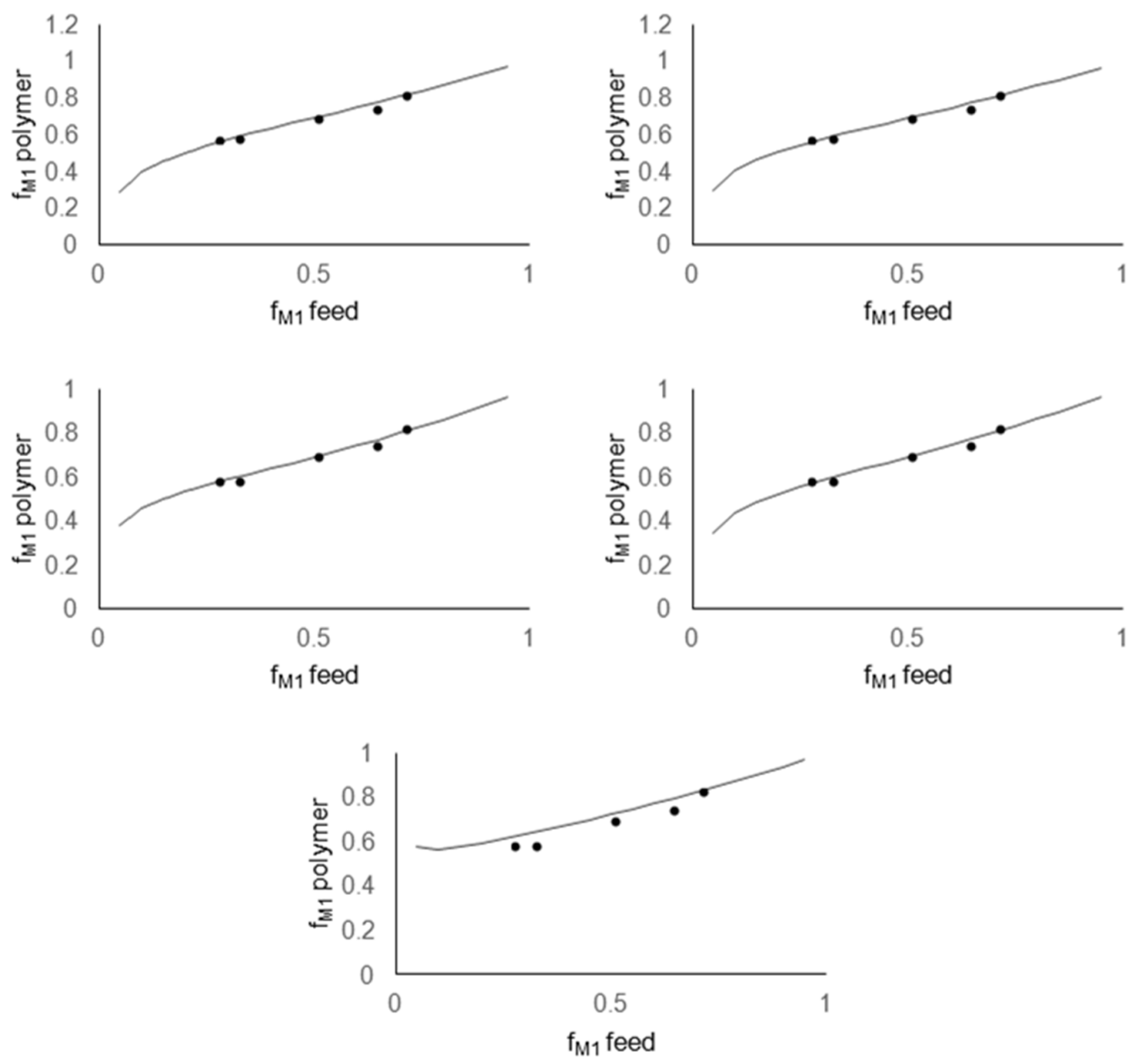

Figure SI 9. Graphs relating the fraction of monomer $1\left(f_{M 1}\right)$ in the feed with the fraction of this monomer in the copolymer (data points) and the predicted compositions for the reactivity ratios that were found (curve) for the copolymerization of 4VP (M1) and SS without $\gamma$-CD, using the following methods: a) curve fitting, b) Fineman-Ross, c) inverted Fineman-Ross, d) Kelen-Tüdõs and e) Tidwell-Mortimer. 

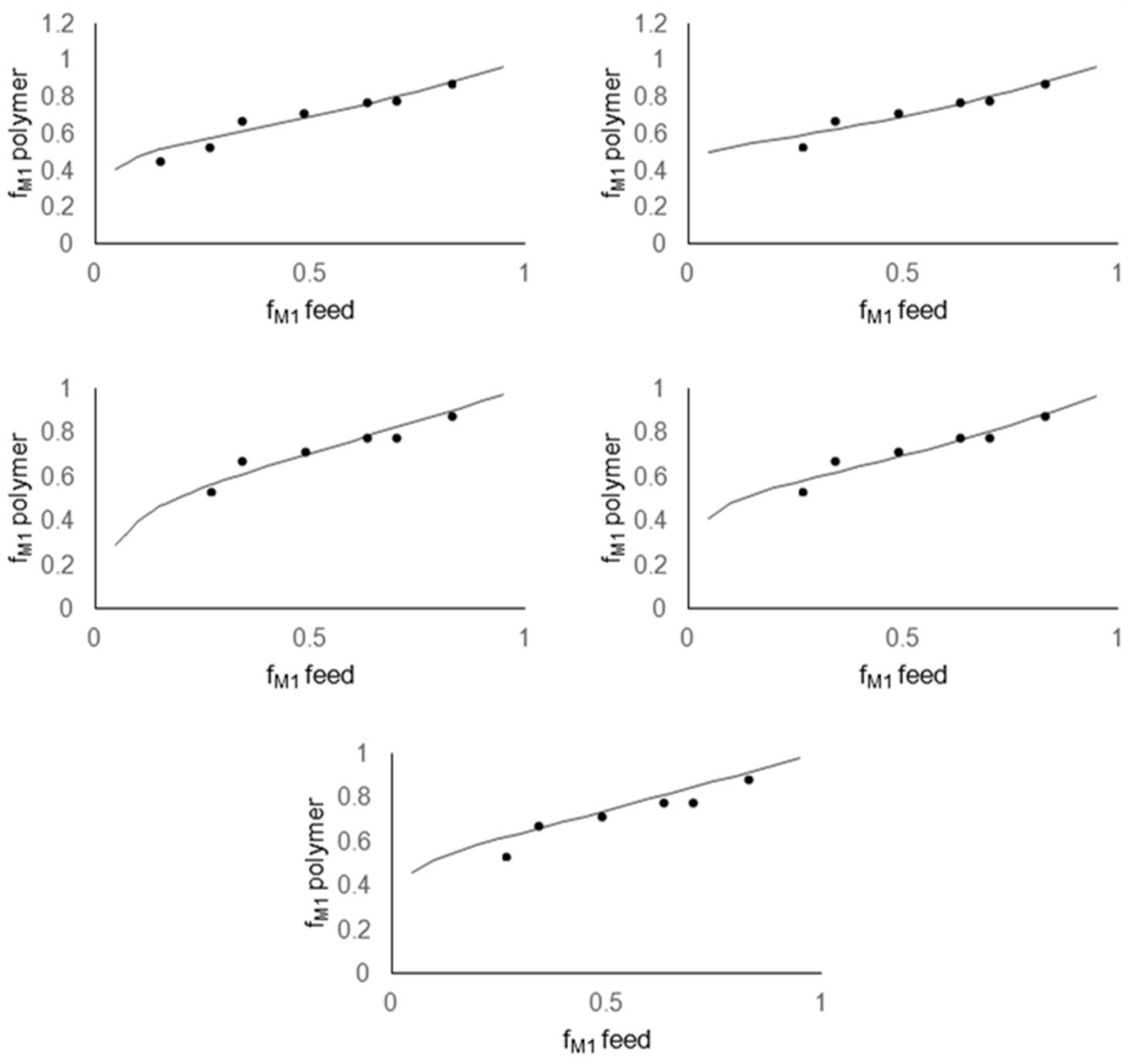

Figure SI 10. Graphs relating the fraction of monomer $1\left(f_{M 1}\right)$ in the feed with the fraction of this monomer in the copolymer (data points) and the predicted compositions for the reactivity ratios that were found (curve) for the copolymerization of 4VP (M1) and SS in the presence of $\gamma-\mathrm{CD}$, using the following methods: a) curve fitting, b) Fineman-Ross, c) inverted Fineman-Ross, d) Kelen-Tüdõs and e) Tidwell-Mortimer. 

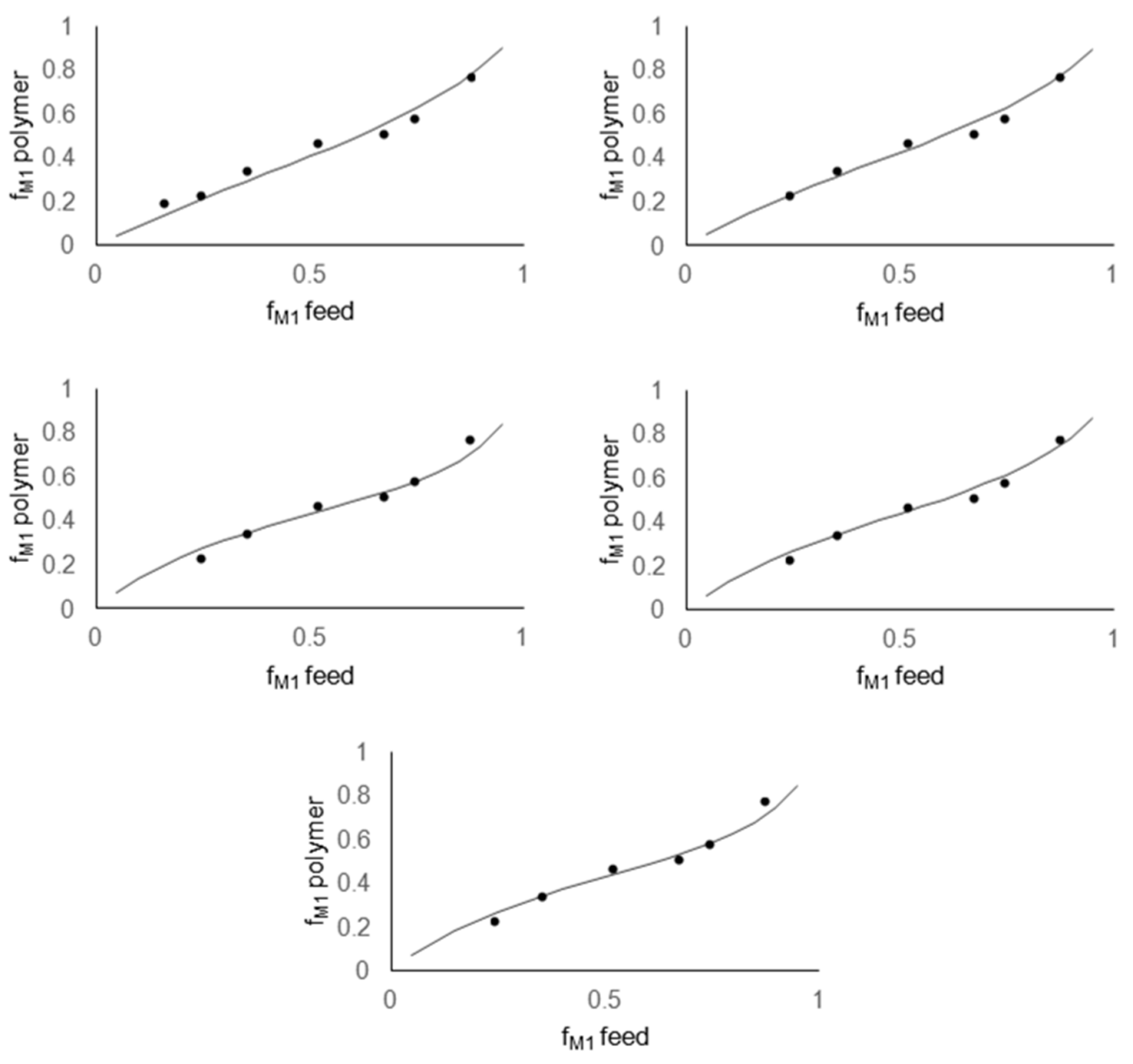

Figure SI 11. Graphs relating the fraction of monomer 1 ( $\left.f_{M 1}\right)$ in the feed with the fraction of this monomer in the copolymer (data points) and the predicted compositions for the reactivity ratios that were found (curve) for the copolymerization of S (M1) and PFS without $\gamma-\mathrm{CD}$, using the following methods: a) curve fitting, b) Fineman-Ross, c) inverted Fineman-Ross, d) Kelen-Tüdõs and e) Tidwell-Mortimer. 

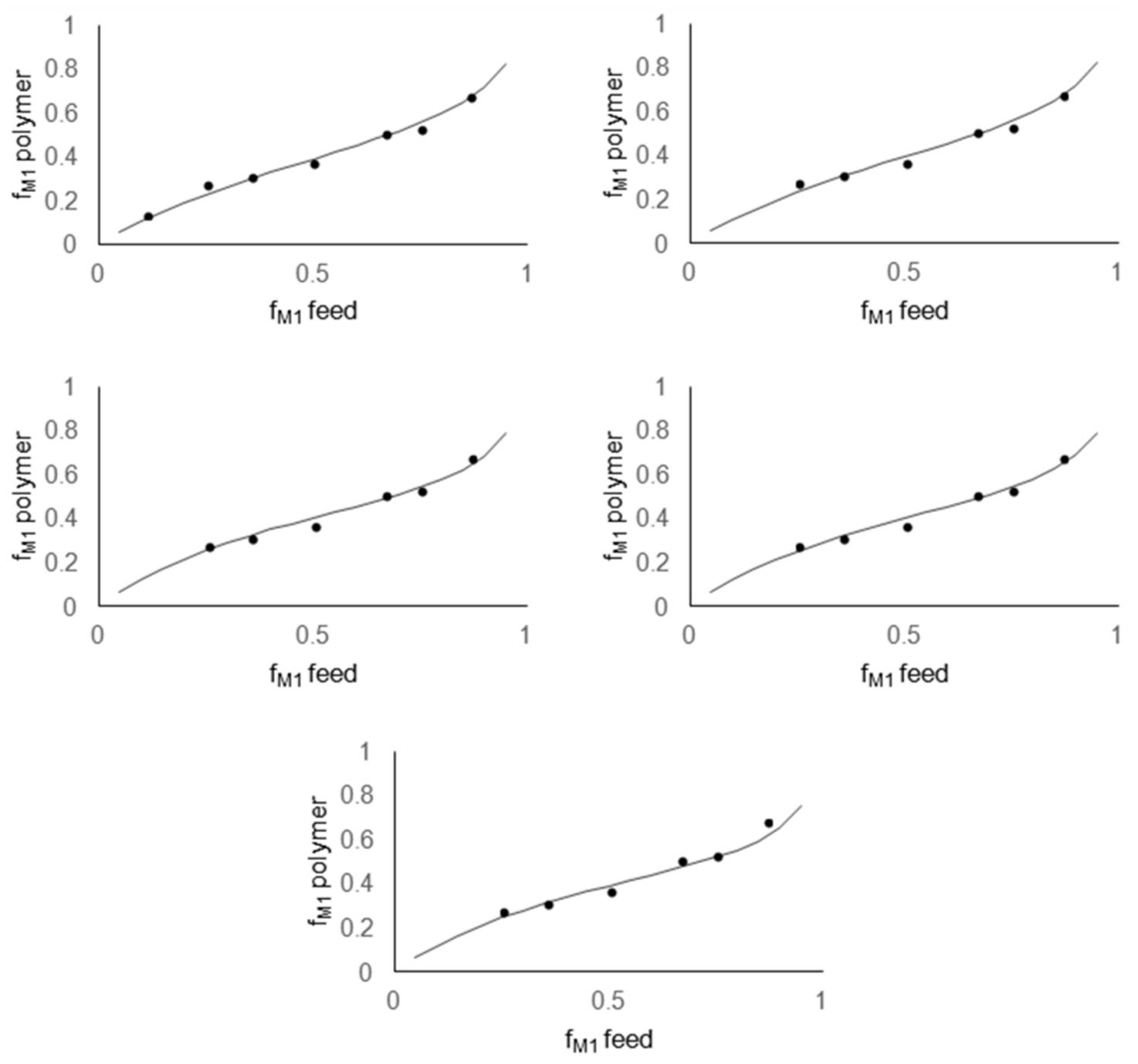

Figure SI 12. Graphs relating the fraction of monomer $1\left(f_{M 1}\right)$ in the feed with the fraction of this monomer in the copolymer (data points) and the predicted compositions for the reactivity ratios that were found (curve) for the copolymerization of S (M1) and PFS in the presence of $\gamma$-CD, using the following methods: a) curve fitting, b) Fineman-Ross, c) inverted Fineman-Ross, d) KelenTüdõs and e) Tidwell-Mortimer. 


\section{Polymer characterization}

Table SI 7. Summary of the SEC results for the copolymers of 4VP with SS.

\begin{tabular}{c|ccccc} 
Polymerization & $\begin{array}{c}\text { Feed ratio } \\
\text { 4VP/SS }\end{array}$ & $\begin{array}{c}\text { Conversion } \\
\left.4 \mathrm{VP} / \mathrm{SS}^{\mathrm{a}}\right)\end{array}$ & $\mathrm{d}(4 \mathrm{VP}) / \mathrm{d}(\mathrm{SS})^{\mathrm{b})}$ & $\begin{array}{c}\overline{M_{n}}\left(\cdot 10^{3}\right. \\
\mathrm{g} / \mathrm{mol})\end{array}$ & $\mathrm{D}$ \\
\hline $4 \mathrm{VP} / \mathrm{SS}$ & $1.00 / 2.17$ & $95 \% / 44 \%$ & 2.12 & 13.3 & 1.99 \\
$\gamma-\mathrm{CD} / 4 \mathrm{VP} / \mathrm{SS}$ & $1.00 / 1.67$ & $100 \% / 62 \%$ & 1.25 & 48.1 & 3.03
\end{tabular}

a) determined by ${ }^{1} \mathrm{H}-\mathrm{NMR}$ after termination of the polymerization

b) determined from the ${ }^{1} \mathrm{H}-\mathrm{NMR}$ spectra of the purified polymers

Table SI 8. Summary of the SEC results for the copolymers of S with PFS.

\begin{tabular}{|c|c|c|c|c|c|}
\hline Polymerization & $\begin{array}{l}\text { Feed ratio } \\
\text { S/PFS }\end{array}$ & $\begin{array}{l}\text { Conversion } \\
\text { S/PFS }\end{array}$ & $\mathrm{d}(\mathrm{S}) / \mathrm{d}(\mathrm{PFS})^{\mathrm{b})}$ & $\begin{array}{c}\overline{M_{n}}\left(\cdot 10^{3}\right. \\
\mathrm{g} / \mathrm{mol})\end{array}$ & $Đ$ \\
\hline S/PFS & $1.00 / 1.00$ & $18 \% / 28 \%$ & 0.75 & 1.72 & 4.14 \\
\hline$\gamma-\mathrm{CD} / \mathrm{S} / \mathrm{PFS}$ & $1.00 / 1.00$ & $18 \% / 29 \%$ & 0.55 & 2.05 & 2.68 \\
\hline
\end{tabular}

\section{${ }^{1} \mathrm{H}-\mathrm{NMR}$ spectroscopy of the purified polymers}

The successful purification of the copolymers, especially the removal of $\gamma$-CD, was shown by ${ }^{1}$ H-NMR spectroscopy (Figure SI 13-14). For the copolymers prepared in $\gamma$-CD only very weak signals for $\gamma-\mathrm{CD}$ (e.g. between 3 and $4 \mathrm{ppm}$ ) are found, indicating that, though not quantitatively, the fast majority of $\gamma$-CD was removed, especially considering the fact that these signals correspond to 48 protons per $\gamma$-CD molecule. For the copolymers of S and PFS the removal of $\gamma$ CD appears nearly quantitative. 


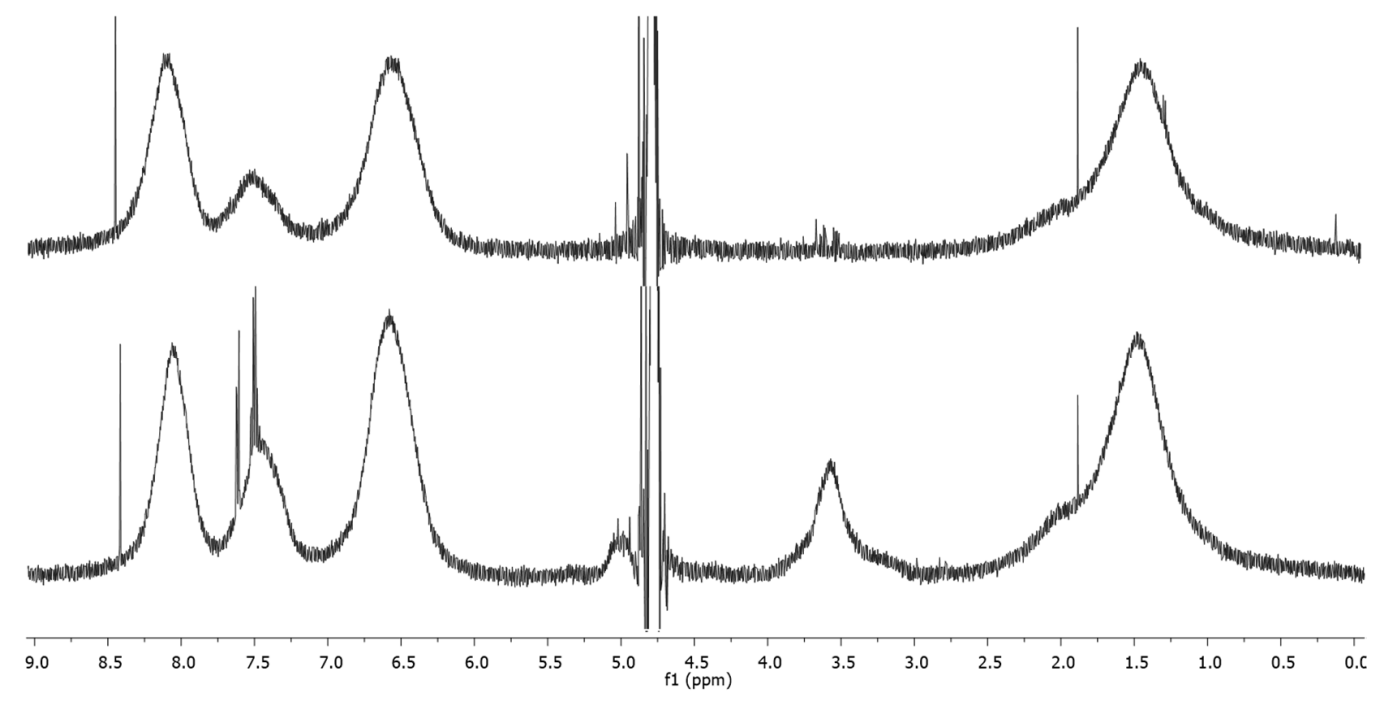

Figure SI 13. ${ }^{1} \mathrm{H}-\mathrm{NMR}$ spectra of the purified copolymers of $4 \mathrm{VP}$ and SS prepared in the absence (top) and presence of $\gamma-\mathrm{CD}$ (bottom) measured in $\mathrm{D}_{2} \mathrm{O}$.

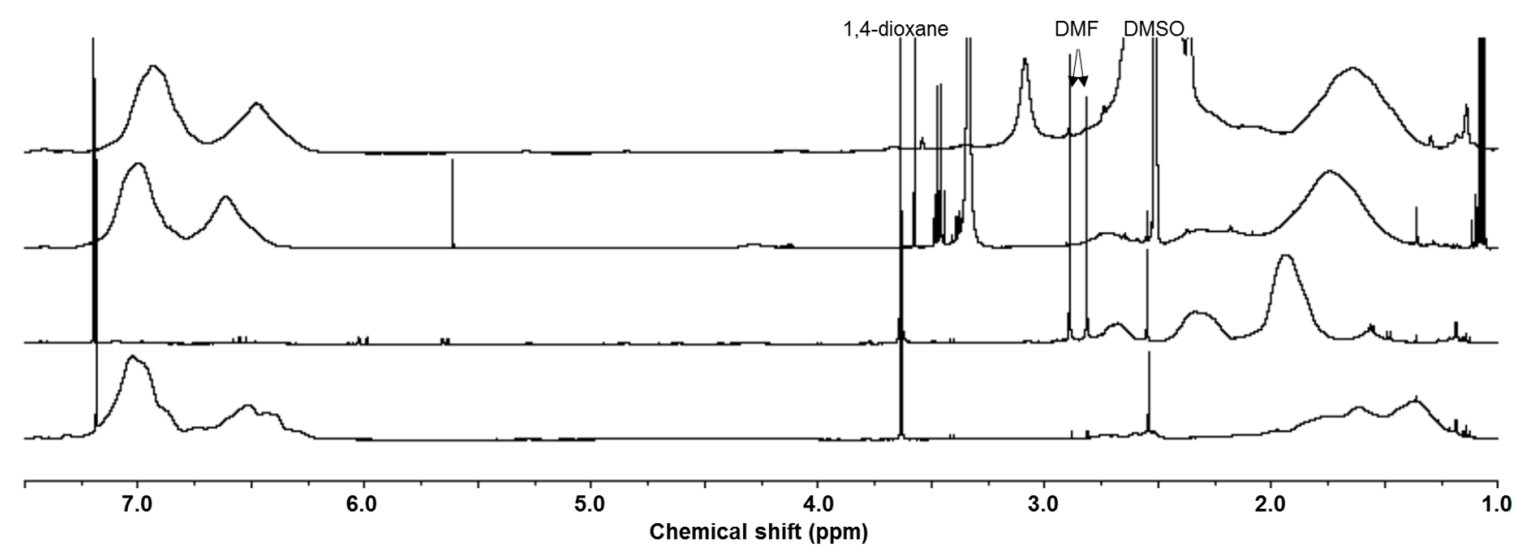

Figure SI 14. ${ }^{1} \mathrm{H}-\mathrm{NMR}$ spectra of (from bottom to top) the purified homopolymers of S and PFS as well as copolymers of S and PFS prepared in the absence and presence of $\gamma$-CD measured in $\mathrm{CDCl}_{3}$. 


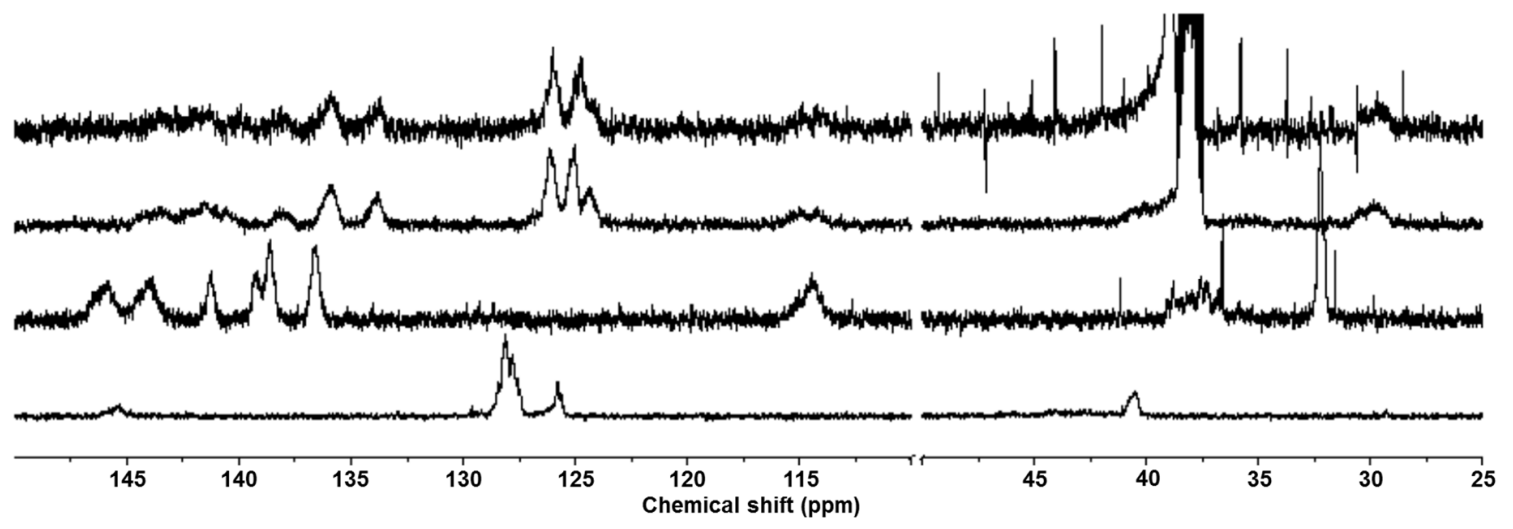

Figure SI 15. ${ }^{13} \mathrm{C}-\mathrm{NMR}$ spectra of (from bottom to top) the purified homopolymers of S and PFS as well as copolymers of S and PFS prepared in the absence and presence of $\gamma$-CD measured in $\mathrm{CDCl}_{3}$.

\section{SEC of the purified polymers}
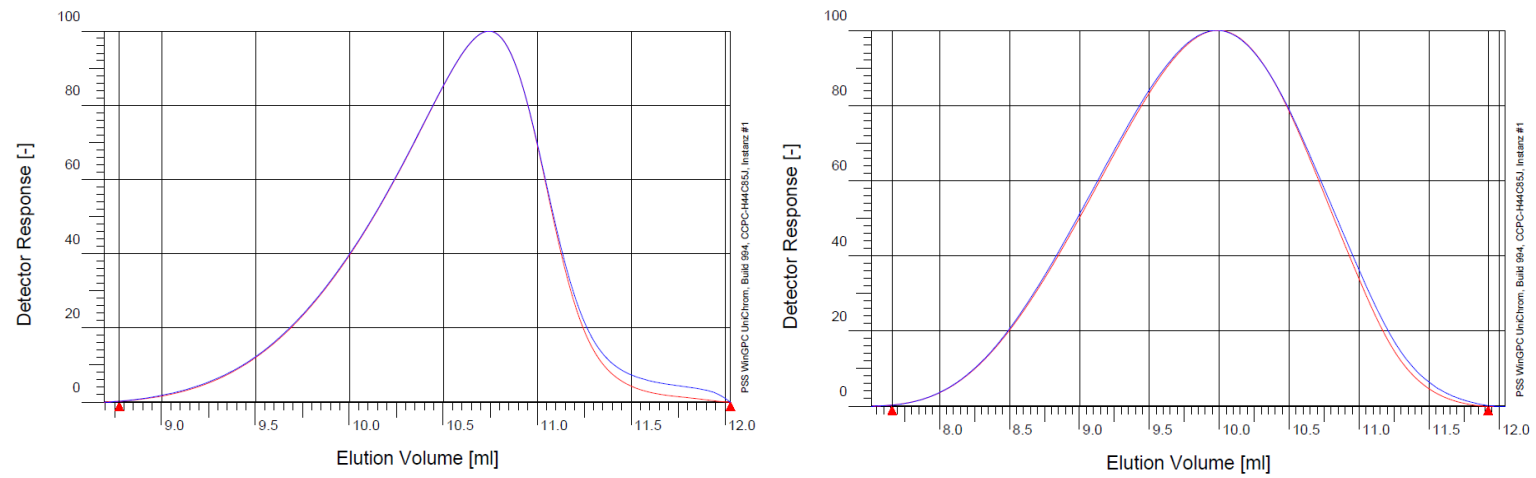

Figure SI 16. SEC chromatograms of copolymers of $4 \mathrm{VP}$ and SS (measured in an aqueous $1 \mathrm{M}$ $\mathrm{NaNO}_{3}$ solution) prepared in the absence (left) and presence (right) of $\gamma$-CD. UV-trace is shown in red, RI-trace is shown in blue. 

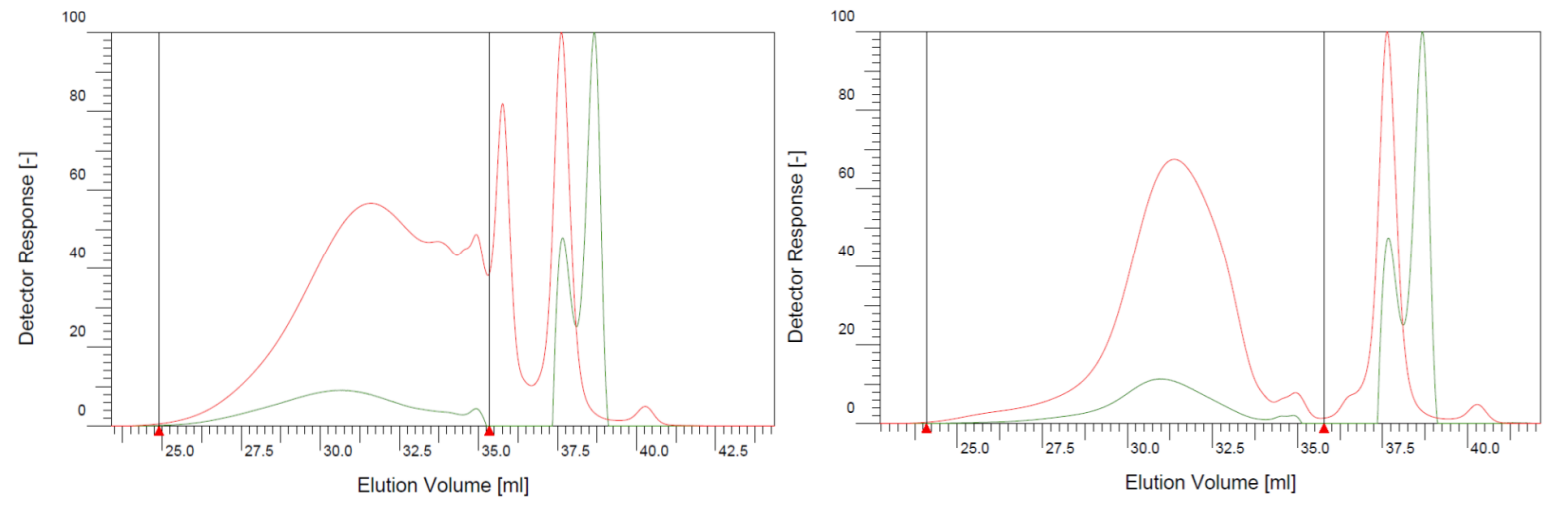

Figure SI 17. SEC chromatograms of copolymers of S and PFS (measured in THF) prepared in the absence (left) and presence (right) of $\gamma$-CD. UV-trace is shown in red, RI-trace is shown in green. The area between the red arrows is used for the determination of the molecular weight. 